\title{
The Use of Influence Tactics in Politicized Organizations: A Look from Gender Perspective
}

\author{
${ }^{*}$ Mahmood A. Bodla1, Rizwan Qaiser Danish ${ }^{1,2}$ \\ ${ }^{1}$ COMSATS Institute of Information Technology, Lahore, Pakistan \\ ${ }^{2}$ Hailey College of Commerce, University of the Punjab, Pakistan \\ *director@ciitlahore.edu.pk
}

\begin{abstract}
The politics is one of the unavoidable constituent of organizational climate in all types of business organizations. Antecedents and consequences of organizational politics and use of influence strategies are very important to consider in an organizational setup when allocating resources and satisfying the interdependencies. However, little is known about the differences among males and females how they use these influence tactics. In this review, the authors have proposed a model which explicitly elaborates the view how the gender differences interact with perceptions of organizational politics when it impacts on job performance. The previous literature supports the fact that males and females differ significantly on perceptions of politics and work performance relationship. The proposed theoretical model for research in multiple dimensions, i.e. power and politics, influence tactics and political behavior may unveil the players' behaviors in politicized organizations.
\end{abstract}

Keywords: Power, Politics, Influence Tactics, Political Behavior, Organizational Politics

\section{Introduction}

Organizational Politics: Interdependence and allocation of resources are political in nature and leaders or managers use some power base while allocating resources. But at managerial level gender imbalance is most prominent among other factors which results in differences in the use of influence tactics at workplace. Influence and power give birth to political behavior and through this powerful tool women can get access to leading positions and their performance can be observed as political strategist. Differences in the use of political behaviors based on gender have been focused in management literature and it shows that women are less skillful in use of political tactics at workplace (Bodla \& Danish, 2008). But there is a clear gap to be filled about the use of power and influence tactics on the base of gender. Gender patterns have been widely discussed in social psychology and there is need to study gender differences in the use of influence tactics within the organizations. In the studies of management, gender refers to social construction of masculinity and feminity, a broader view as compared to biological sex view. Some explanation regarding this phenomenon state that there is incompatibility between stereotypes of women and stereotypes of managers. Some have viewed it in the perspective of lack of fit theory (Heilman \& Okimoto, 2007) and incompatible social roles (Eagly \& Karau, 2002). Although power imbalances are widely spread in organizations and a large number of studies have been dedicated to discover the causes of differences between males and females, but these are inconclusive. Social influence attempts are widely judged through gender differences. Women are perceived differently when they engage in behaviors related to power as men do. Women lack in political competency and thus consider political activity as distasteful (Arroba \& James, 1988). That's why fewer women enter into some top level management.

Power and Politics: Pfeffer (1981) defined the organizational politics as the intensive strike of power, supremacy and influence. A large number of studies focus on the intentions, the respective motives and the behaviors of individuals acting politically within organizational settings (Coopey \& Burgoyne, 2000; Diefenbach, 2007; Grossmann, 2006). But these studies are fragmented, isolated and non conclusive, specifically with regard to the patterns of men and women in the use of power and politics. However if women succeed in male specific tasks even then they have to face social rejection (Heilman et al., 2004). Ability to prove manly task at work required with greater intensity by women as compared to men at work place. Schein (2001) has used expression "thinks manager, think male". 


\section{Political Behavior}

Although organizations have made much progress in last decades but women could not be represented at top management level (Singh \& Vinnicombe, 2003). This has been explained by differences in the use of political behaviors at workplace and less skill in the use of influence tactics. If women could get more managerial positions and have been equipped with better skills in influencing others, they could get more leadership positions and consequently their performance boost up. An organization can be viewed as a political system, a network of interdependent members using power, influence, and political maneuvering to achieve their goals (Pfeffer, 1981; Mintzberg, 1983; Ferris, Harrell-Cook \& Dulebohn, 2000). More specifically, politically motivated behaviors are "those activities that are not required as part of one's formal role in the organization, but that influence, or attempt to influence, the distribution of advantages and disadvantages within the organization" (Farrell \& Peterson, 1982). In a strictly neutral sense, the phrase "political behavior" denotes behaviors designed to influence outcomes, behaviors beyond those formally prescribed by the organization. Because the behaviors are not formally prescribed by the organization, and because of the inherent power and status differentials in organizational hierarchies, political actors are often motivated to seek self-serving ends, regardless of the benefit to the larger organization. Hence, political behavior in organizations suggests a normative, unethical connotation. This latter interpretation of "organizational politics" may be viewed as a subset of another closely related theoretical construct: impression management.

Clearly, the degree and consequence of these political behaviors may vary from the relatively inoffensive flattery and ingratiation exhibited towards superiors, to the Machiavellian attempts to influence outcomes through sabotage, deception and character assassination. In a decisive study based on interview data, Allen, Madison, Porter, Renwick and Mayes (1979) presented a taxonomy of political behavior. In descending order of reported frequency, the eight political behaviors in the taxonomy were: (1) Attacking or blaming others, (2) Using information as a political tool, (3) Creating a favorable image (impression management), (4) Developing a base of support, (5) Praising others (ingratiation), (6) Forming power coalitions with allies, (7) Associating with influential people, and (8) Creating obligations (reciprocity).The explanatory value of this taxonomy is demonstrated in the findings that information is power and, hence, its selective disclosure or distortion increases the influence of the person possessing and manipulating its disclosure. For example, organizational members with expertise in a given area may use their knowledge to influence or constrain decisions made by those above them in the hierarchy and thus advantageously affect outcomes (Larson \& King, 1996). In a series of studies Mowday $(1978,1979)$ operationalized five specific types of information/ influence tactics: threats, appeals to legitimate authority, reasoning and persuasive arguments, reciprocity reflected in exchange of rewards or favors, and manipulation. His research suggests that the choice of influence strategy is dependent on the positional power of the target of that influence and the nature of the issue communicated.

Subsequent research confirms that the "softer" tactics of reason and reciprocity are more common in upward influence attempts than the "harder" tactics of threat, manipulation or appeal to authority. Conversely "harder" tactics are more common in downward influence attempts (Yukl \& Falbe, 1991; Rao \& Schmidt, 1995).Depending on the target of influence, and the degree to which organizational members seek to advantageously influence outcomes, those organizational members will enact strategic, communication behaviors ranging from gentle flattery at best, to Machiavellian manipulation at worst. The original taxonomy has eight political behaviors, but Sussman, Adams, Kuzmits and Rocho (2002) excluded 'associating with influential people' tactic (cited infrequently in the Allen et al. study) because its definition appeared to overlap considerably that of another tactic. The politically motivated behaviors and their brief illustrations as used in the survey were as follows:

- Attacking or blaming others. This behavior is often associated with scapegoating - blaming others for a problem or failure. It may also include trying to make a rival look bad by minimizing his or her accomplishments.

- Using information as a political tool. This behavior may include withholding important information when doing so might further an employee's political interests. This type of behavior can also include information overload, for example, to bury or obscure important (but potentially damaging) details that the employee hopes goes unnoticed. 
- Creating and maintaining a favorable image. This behavior includes drawing attention to one's successes and the successes of others, creating the appearance of being a "player" in the organization, and developing a reputation of possessing qualities considered important to the organization. The behavior also includes taking credit for the ideas and accomplishments of others.

- Developing a base of support. Examples of this behavior include getting prior support for a decision before a meeting is called and getting others to contribute to an idea to secure their commitment.

- Ingratiation: praising others. This behavior includes praising others and establishing good rapport for self-serving purposes.

Organizational jargon for this behavior includes "buttering up the boss," "apple polishing," and "brownnosing."

- Developing allies and forming power coalitions. This behavior includes developing networks of coworkers, colleagues, and/or friends within and outside the organization for purposes of supporting or advocating a specific course of action.

- Creating obligations and reciprocity. This behavior includes performing favors to create obligations from others, commonly known as, 'You stab my back and I'll stab yours.'

\section{Expansion in Influence Tactics}

Influence tactics has been viewed from different perspectives but generally these are the behaviors used to change the opinions, attitudes or behavior of the other person or persons (Hughes, Ginnett, \& Curphy, 1993). Influence tactics have been categorized in various ways by different researchers (Kipnis, Schmidt, \& Wilkinson, 1980). Yukl and Falbe (1990); Falbe and Yukl (1992) recognized nine influence tactics: legitimizing, rational persuasion, inspirational appeal, consultation, exchange, personal appeals, ingratiation, pressure, and coalition which were later categorized by Barbuto, Scholl, Hickox and Boulmetis (2001) as "hard" or "soft" based on targets' levels of resistance in relation to influencer. Hard, also known as forceful tactics, include legitimizing, exchange, pressure, and coalition. Soft tactics are more interpersonal and include rational persuasion, inspirational appeals, consultation, ingratiation, and personal appeals (Barry \& Shapiro, 1992). Kinpis et al. (1980) identified empirically eight major influence tactics which opened new horizons for the study of influence Behaviors in organizations. These are assertiveness, ingratiation, rationality, exchange upward appeals, coalition, sanctions, and blocking. The study setting comprised of 165 managers working in US that were interviewed to generate the item list, followed by a quantitative questionnaire to quantify influences to their bosses $(n=225)$, coworkers $(n=285)$ and subordinates $(n=244)$. Schmidt and Yeh (1992) validated the inventory proposed by Kipnis et al. (1980) across different cultures with supervisors and managers from Australia $(n=126)$, England $(n=121)$, Taiwan $(n=2,231)$ and Japan $(n=355)$. Although they confirmed the structural generalizability of eight-dimension but did not focus on the division of the specific items according to different factors, e.g., assertiveness was defined by only one item in Australia, three in Taiwan and cross loaded with items tapping sanction, reason, bargaining and higher authority in the other two cultures. Schriesheim and Hinkin (1990) used four independent samples ( $n=34$ judges, $n=251$ MBA students; $n=281$ MBA students; $n=181$ clerks \& secretaries) in the U.S. and verified empirically six influence tactics suggested by Kipnis et al. (1980), but they recommended to drop "blocking" and "sanction" to enhance validity and reliability.

The list of these tactics then went on expanding. Yukl and Falbe (1990) replicated the study of Kipnis et al. (1980), but they offered the distinction of agent and the target in their investigation $(n=237$ working MBA students and managers in the U.S.). They affirmed the changes proposed by Schriesheim and Hinkin (1990). They also suggested two new additions to the influence tactics inventory, i. e. inspirational appeals and consultation. The inspirational appeals dealt with the gap between charismatic and transformational leadership and the consultation was more concerned with influence through employees' participation and involvement. Yukl and Tracey (1992) and Yukl, Falbe and Youn (1993) evaluated the effectiveness of nine influence tactics ( $\mathrm{n}=128$ managers, 526 subordinates, 543 peers and 128 superiors) and focused on the combined usage of nine influence tactics after providing a qualitative analysis of their pattern $(n=145$ MBA students). They used a priori approach, and merge assertiveness and upward appeal into a single tactic, pressure. These studies included personal appeals and legitimating into the list to consider the focal person's personal and positional power, thus producing a total of nine tactics. Kennedy, Fu, and Yukl (2003) evaluated the perceptions of employees in 12 different cultures about the effectiveness of 16 influence tactics ( $n=103$ to 
187 managers). The list was fully expanded to encompass a total of 16 tactics. New additions comprised of collaboration, persistence, informal approach, gifting and socializing. Moreover rationality was splitted up into three distinct tactics: rational persuasion, written explanation, and appraising. But according to a recent study by Leong, Bond and Fu (2007) inclusion of more tactics in this list is a just temporary effort because there was much left undone to confirm the consistency and construct validity. Whether these additions increase the explanatory strength of the list provided by Kipnis, Schmidt and Wilkinson (1980) or not, and to what extent have been questions that need to be answered. However these attempts led to the broader framework and more coherent conceptualization of influence behaviors in organizations.

Influence strategies: Carli and Eagly (1999) suggested that interaction among women groups devalue their task related contributions and relational behaviors are more dominant. Self presentation and self monitoring emerge as influence tactic. Men and women both perceive aggressive influence tactics negatively but women are highly rated when they use friendly influence strategies. Sun and Bond (2000), Fu, Kennedy, Tata, Yukl, Bond and Peng (2004) have tried to explain the influence behaviors at higher abstraction level and they argued that a range of influence tactics can be summarized into a few wide strategies. Based on Kinpis et al. (1980)'s view of Chinese tactics, Sun and Bond (2000) described two major dimensions which they coined as Gentle Persuasion and Contingent Control. But on the other hand, Fu et al. (2004) developed a three factor model based on the data collected from managers of 12 different nations and they recognized it as Persuasive Strategy, Assertive Strategy and Relationship-based Strategy. In another stream of research, Kipnis and Schmidt (1985) focused on theory-based conceptualization of influence strategies. They proposed a classification of three Meta categories: Hard Strategy, Soft Strategy and Rational Strategy. Sun and Bond (1999) were the pioneer to create a model of Meta strategies using a bottom-up approach $(n=218$ Chinese managers in Mainland China). They extracted a two-factor model from 58 items of influence tactics, i. e., Contingent Control and Gentle Persuasion. Sun and Bond (2000) interviewed managers in Guangzhou $(\mathrm{n}=372)$, China and validated the two-factor composition they proposed one earlier in 1999. They also evaluated directional differences in the use of the two strategies and involved personality variables to predict strategy use. Gift-giving, face-giving, long-term interpersonal perspectives, etc. were also recognized to better fit the local context for some studies in Confucian cultures (Sun \& Bond, 2000; Fu \& Yukl, 2000). In this way the inventory of tactics expanded from the original 8 to 16 in later studies (Kennedy, Fu \& Yukl, 2003; Fu et al., 2004). Fu et al. (2004) evaluated 16 tactics by managers from 12 cultures; and related the Meta strategies to social beliefs or context. They proposed a three-factor model: Persuasive Strategy, Relationship-Based Strategy and Assertive Strategy.

\section{Proposed model to study Gender and influence tactics}

The gender differences in political perceptions are prominent in most of the organizations where the males are more dominant and influential at workplaces than women. According to Mann (1995) the position of males in power, influence and leadership are stronger in organizations than women because the organizational structure and culture is more easy and flexible for males. Organizational politics is in fact the advanced form of power. Where the males practice more power and influence in majority of the organizations as the top level management of majority of the organizations is handled and controlled by the males. Arroba and James (1988) stated that the males are the more dominant workforce in the organizations as the organizational hierarchy, setup, structure, goal and vision is explicitly designed by the top level managers who are generally men, than women. The political behavior at workplaces also matters in justifying the position and attaining the power by a gender. Broussine and Fox (2003) posited a view that in comparison to males the females' political behavior is weak and less impressive as the top level female managers in certain organizations have to face difficulties in dealing with customers and organizational affairs than male because of the unsuitability of certain cultural factors but not due to women inappropriateness.

A study by Burgoon, Dillard and Doran, (1983) showed that "participants were more persuaded by men who used a direct and aggressive influence strategy than by women who used the same strategy". Tepper, Brown and Hunt (1993) found that "men who employed stronger upward influence tactics received higher performance ratings and more career-related mentoring than women who employed these same tactics". In a study by Bodla and Danish (2008), significant differences among male and females were found in their perceptions of a politicized environment and women reported higher level of politics which resulted in their 
stress level to increase and ultimately developing the intentions to quit the organizations. Future studies may be conducted to investigate contextual nature of gender, along with focusing on gender differences. When men and women are considered as leaders both have some values, it is equivocally important that we understand the differences that may occur either as a result of gender or as a result of workers' reactions to leaders based on gender. Future studies, as well as the reexamination of previous studies, may eventually help us come closer to answering the question: Are men different from women in the use of influence tactics? More specifically the following propositions are suggested to address the phenomenon.

Proposition 1: Need for power will be positively correlated with influence tactics in politicized organizations. Proposition 2: Political Behavior will affect the performance of employees through perceptions of organizational politics.

Proposition 3: Perceptions of politics will be higher for female employees as compared to male employees in politicized organizations.

Proposition 4: Male employees will use harder influence tactics more than softer influence tactics while female employees will use softer influence tactics more than harder influence tactics in the organizations.

Proposition 5: Perceptions of organizational politics will mediate the relationship between political behavior and employee's performance

\section{Proposed Model of Use of Influence Tactics}

\section{References}

Allen, R. W., Madison, D. L., Porter, L. W., Renwick, P. A. \&Mayes, B. T. (1979). Organizational Politics: Tactics and Characteristics of its Actors. California Management Review, 22, 77-83.

Arroba, T. \& James, K. (1988).Are Politics Palateable to Women Managers? How Women Can Make Wise Moves at Work. Women in Management Review, 3(3), 123.

Barbuto, J. E., Scholl, R. W., Hickox, C. F. \& Boulmetis, J. (2001). A field study of the relation between leaders' anticipation of targets' resistance and targets' report of influence tactics used by leaders in dyadic relations. Psychological Reports, 88, 835-944. 
Barry, B. \& Shapiro, D. L. (1992). Influence tactics in combination: The interactive effects of soft versus hard tactics and rational exchange. Journal of Applied Social Psychology, 22, 1429-1441.DOI: 10.1111/j.1559-1816.1992.tb00958.x

Bodla, M. A. \& Danish, R. Q. (2008).The gender differences in the relationship between perceptions of organizational politics and work performance. The International Journal of Knowledge, Culture and Change Management, 8(6), 9-18.

Broussine, M. \& Fox, P. (2003).The politics of researching gender in organizations. Management Research News, 26(8), $27-37$.

Burgoon, M., Dillard, J. P. \& Doran, N. E. (1983).Friendly or unfriendly persuasion: The effects of violations by males and females. Human Communication Research, 10, 283-294.DOI: 10.1111/j.14682958.1983.tb00018.

Carli, L. L. \& Eagly, A. H. (1999).Gender Effects on Social Influence and Emergent Leadership. In Gender and Work, Powell, G., Sage Publications, London.

Coopey, J. \&Burgoyne, J. (2000).Politics and Organizational Learning. Journal of Management Studies, 37(6), 869-885.

Diefenbach, T. (2007).The Managerialistic Ideology of Organizational Change Management. Journal of Organizational Change Management, 20(1), 126144.http://dx.doi.org/10.1108/09534810710715324

Eagly, A. H. \& Karau, S. J. (2002).Role congruity theory of prejudice toward female leaders. Psychological Review, 109, 573-598.doi:10.1037/0033-295X.109.3.573

Falbe, C. \&Yukl, G. (1992).Consequences for managers of using single influence tactics and combinations of tactics. Academy of Management Journal, 35, 638-652.

Farrell, D. \& Peterson, J. (1982).Patterns of Political Behavior in Organizations. Academy of Management Review, 7, 403-428.

Ferris, G. R., Harrell-Cook, G. \& Dulebohn, J. H. (2000). Organizational Politics: The Nature of the Relationship between Politics Perceptions and Political Behavior. In S. B. Bacharach and E. J. Lawler (eds.).Research in the Sociology of Organizations, 17 (JAI Press, Greenwich, CT), 89-130.

Fu, P. P. \& Yukl, G. (2000).Perceived effectiveness of influence tactics in the United States and China. Leadership Quarterly, 11, 51-266.

Fu, P. P., Kennedy, J., Tata, J., Yukl, G., Bond, M. H. \& Peng, T. (2004). The impact of societal cultural values and individual social beliefs on the perceived effectiveness of managerial influence strategies: A meso approach. Journal of International Business Studies, 35, 284-305.

Grossmann, M. (2006). The Organization of Factions. Interest Mobilization and the Group Theory of Politics. Public Organization Review, 6(2), 107-124.DOI 10.1007/s11115-006-0002-3

Heilman, M. E. \& Okimoto, T. G. (2007). Why Are Women Penalized for Success at Male Tasks? The Implied Communality Deficit. Journal of Applied Psychology, 92(1), 81.

Heilman, M. E., Wallen, A. S., Fuchs, D. \& Tamkins, M. (2004).Penalties for Success: Reactions to Women Who Succeed at Male Gender-Typed Tasks. Journal of Applied Psychology, 89(3), 416-427.

Hughes, R. L., Ginnett, R. C. \& Curphy, G. J. (1993). Leadership: Enhancing the lessons of experience. Boston: Irwin.

Kennedy, J. C., Fu, P. P. \& Yukl, G. (2003). Influence tactics across twelve cultures. Advances in global leadership, 3, 127-147.

Kipnis, D. \& Schmidt, S. M. (1985).The language of persuasion. Hard, soft or rational: Our choice depends on power, expectations and what we hope to accomplish. Psychology Today, 4, 40-46.

Kipnis, D., Schmidt, S. M. \& Wilkinson, I. (1980). Intraorganizational influence tactics: Explorations in getting one's way. Journal of Applied Psychology, 65, 440-452.

Larson, E. \&King, J. (1996). The Systematic Distortion of Information: An Ongoing Challenge to Management. Organizational Dynamics, 24, 49-61.

Leong, J. L. T., Bond, M. H. \& Fu, P. P. (2007).Perceived effectiveness of influence strategies among Hong Kong managers. Asia Pacific Journal of Management, 24(1), 75-96.

Mann, S. (1995). Politics and power in organizations: Why women lose out. Leadership \& Organization Development Journal, 16(2), 9.DOI 10.1108/01437739510082271

Mintzberg, H. (1983). Power in and Around Organizations, Prentice Hall, Englewood Cliffs, NJ.

Mowday, R. T. (1978). The Exercise of Upward Influence in Organizations. Administrative Science Quarterly, 23, 137-156. URL: http://www.jstor.org/stable/2392437 
Mowday, R. T. (1979). Leader Characteristics, Self-Confidence, and Methods of Upward Influence in Organizational Decision Situations. Academy of Management Journal, 22, 709-725. URL: http://www.jstor.org/stable/255810

Pfeffer, J. (1981). Power in Organizations. Pitman, Boston.

Rao, A. \& Schmidt, S. M. (1995). Upward Impression Management: Goals, Influence Strategies, and Consequences. Human Relations, 48, 147-167.doi: 10.1177/001872679504800203

Schein, V. E. (2001). A global look at psychological barriers to women's progress in management. Journal of Social Issues, 57, 675.DOI: 10.1111/0022-4537.00235

Schmidt, S. M. \&Yeh, R. S. (1992). The structure of leader influence: A cross-national comparison. Journal of Cross-Cultural Psychology, 23, 251-264.doi: 10.1177/0022022192232009

Schriesheim, C. A. \& Hinkin, T. R. (1990). Influence Tactics Used by Subordinates: A Theoretical and Empirical Analysis and Refinement of the Kipnis, Schmidt, and Wilkinson Subscales. Journal of Applied Psychology, 75, 246-257.

Singh, V. \& Vinnicombe, S. (2003).The 2003 female FTSE index. Women pass a milestone: 101 directorships on the FTSE 100 boards. Cranfield: Cranfield University, Cranfield School of Management.

Sun, H. F. \& Bond, M. H. (1999).The structure of upward and downward tactics of influence in Chinese organizations. In J. C. Lasry, J. Adair, \& K. Dion (Eds.), Latest contributions to cross-cultural psychology ( 286-299). Amsterdam: Swets and Zeitlinger.

Sun, H. \& Bond, M. H. (2000). Choice of influence tactics: Effects of the target person's behavioral patterns, status and the personality of the influencer. In J. T. Li, A. S. Tsui, \& E. Weldon (Eds.). Management and organizations in the Chinese context, (283-302). New York: Macmillan.

Sussman, L., Adams, A. J., Kuzmits, F. E. \& Rocho, L. E. (2002). Organizational Politics: Tactics, Channels, and Hierarchical Roles. Journal of Business Ethics, 40(4), 313-329.

Tepper, B. J., Brown, S. J. \& Hunt, M. D. (1993). Strength of subordinates' upward influence tactics and gender congruency effects. Journal of Applied Social Psychology, 23, 1903-1919.

Yukl, G. \& Falbe, C. (1990). Influence tactics and objectives in upward, downward, and lateral influence attempts. Journal of Applied Psychology, 75, 132-140.

Yukl, G. \& Falbe, C. M. (1991). Importance of difference power sources in downward and lateral relations. Journal of Applied Psychology, 76, 416-423.

Yukl, G. \& Tracey, B. (1992). Consequences of influence tactics used with subordinates, peers, and the boss. Journal of Applied Psychology, 77, 525-535.

Yukl, G., Falbe, C. M. \& Youn, J. Y. (1993).Patterns of influence behavior for managers. Group and Organizational Management, 18, 5-29. 